\title{
Predicting the Flow Velocity at the Toe of A LABYRINTH STEPPED SPILLWAY
}

\author{
Jaafar S. Maatooq \\ Civil Engineering Department, University of Technology, Baghdad, Iraq
}

\begin{abstract}
The velocity at the toe of a spillway is a major variable when designing a stilling basin. Reducing this velocity leads to reduce the size of the basin as well as the required appurtenances needed for dissipating the surplus kinetic energy of the flow. If the spillway chute is able to dissipate more kinetic energy, then the resulting flow velocity at the toe of the spillway will be reduced. Typically, a stepped spillway is able to dissipate more kinetic energy than that of a smooth surface. In the present study, the typical uniform shape of the steps has been modified to a labyrinth shape. It is logical to expect that the labyrinth shape will lead to dissipate more kinetic energy. This impression comes through creating more regions of circulation and turbulence along the lateral sides of each step in addition to those that occur towards the streamwise. This action can also reduce the jet velocities near the surfaces, thus minimizing cavitation. At the same time, the increase in circulation regions will maximize the opportunity for air entrainment, which also helps to dissipate more kinetic energy. The undertaken physical models consisted of three labyrinths of stepped spillways with magnification ratios (width of the labyrinth to width of conventional step) $\mathrm{W}_{\mathrm{L}} / \mathrm{W}$ are 1.1, 1.2, and 1.3 as well as testing a conventional stepped spillway $\left(\mathrm{W}_{\mathrm{L}} / \mathrm{W}=1\right)$. Two empirical forms of the coefficient are proposed, one for labyrinth shape stepped spillway denoted $\mathrm{K}_{\mathrm{L}}$ and another for conventional stepped spillway denoted $\mathrm{K}_{\mathrm{S}}$. Once the value of the coefficient is known, the actual flow velocity at the toe of a stepped spillway can easily be computed without having to resort to measurements on-site. It is concluded that the spillway chute coefficient is directly proportional to the labyrinth ratio and its value decreases as this ratio increases.
\end{abstract}

Keywords: Stepped spillway; Labyrinth spillway; Energy dissipation; Labyrinth shape; Magnification ratio; Chute coefficient.

\section{حساب سرعة الجريان عند قامة المطقح المدرج على شكل متاهة}

$$
\text { جعفر صادق معتوق }
$$

الملخص: تعتبر السر عة عند قدمة المطفح من المتغيرات الرئيسية عند تصميم أحواض التسكين. وبالتالي التقليل من تلك السرعة يعني التقليل من الحجم المطلوب لحوض الته التسكين وكذلك من الملحقات الخاصة بتبديد طاقة الجريان الحركية. فعندما يكون سطح المطفح قادر على تبديد مقدار أكبر من طاقة الجريان الحركية حينها ستكون سرعة الجريان الجريان الواصلة

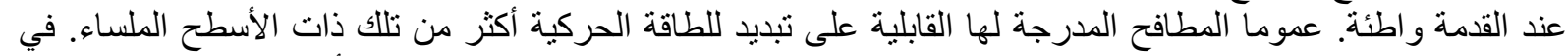

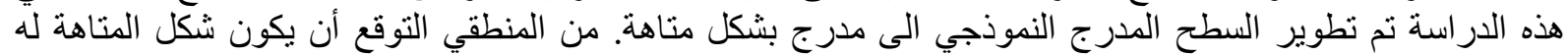

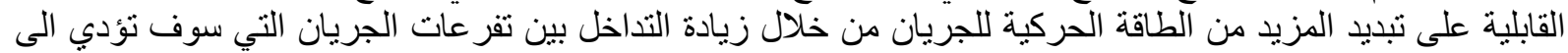

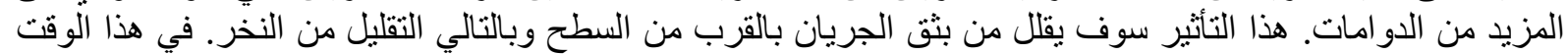
زيادة مناطق الدوامات سوف تزيد من فرصة تداخل الهواء مع الجريان الذي بدوره يساعد على تبلى تبديد المزيد من الطاقة

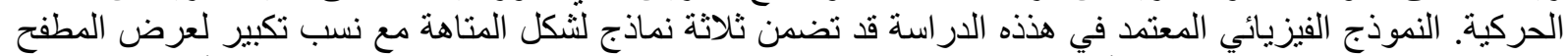

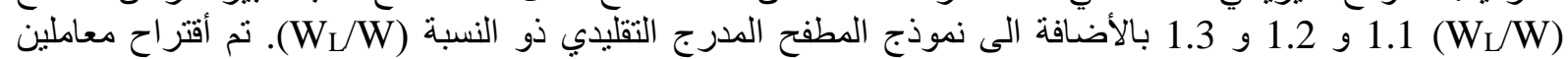

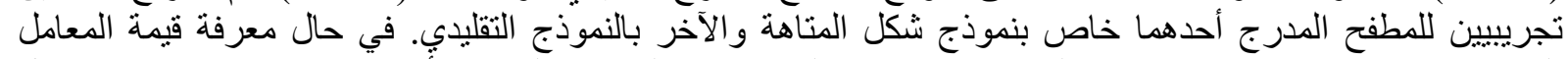

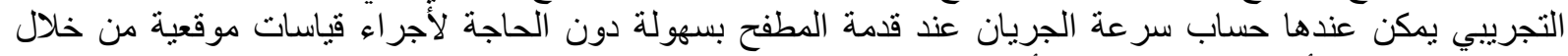
النتائج يمكن القول بأن معامل المطفح قد تأثر بشكل مباشر مع نسبة التكبير وبالتالي قيمته تقل مع الزيادة في تلك النسبة. 


\section{INTRODUCTION}

The behaviour of flow down conventional uniform stepped spillways has been investigated both experimentally and numerically by numerous researchers. Some studies have been conducted into modifications of the conventional configuration of a stepped spillway to improve its hydraulic performance by increasing the kinetic energy dissipation and/ or enhancing the resistance to cavitation. Such modifications included; inclined upward steps, installing end sills, adding baffle blocks at the downstream end of each step, turbulence manipulators and macro-roughness systems consisting of concrete blocks (Manso and Schleiss, 2002; Chanson and Gonzalez, 2004; EL-Jumaily and Al-Lami, 2009). With respect to the values of the flow velocity at the toe of the spillway, Bradley, and Paterka (1957) and more recently Zahra et al. (2015) have applied a correction coefficient, $\mathrm{Cf}$ to the theoretical velocity to give the actual velocity. In these studies, the hydraulic effects and the roughness along the chute of the spillway are implicitly reflected in this coefficient. Abdul-Mehdi et al. (2016) from the laboratory study which has been conducted on steps roughed by three different sizes of gravel. The authors concluded that the energy dissipation increases with the increasing the size of the gravel and the maximum per cent of this increase was $16.73 \%$ as compared with the traditional steps without roughness by gravel for the same geometric and hydraulic conditions. Moghaddam et al. (2017) adopted the reverse gradient with sill installed at the edge of each step of the stepped spillway as an attempt for development. The experimental program has been conducted to test the advantage of this development. The change of; reverse gradient, sill height and sill thickness are the aims to increase the ability of the stepped surface of the spillway to dissipate more kinetic energy. The results show appreciable advantages of such attempts especially with higher reverse gradient and less thickness of sill.

From all the aforementioned researches, the key advantage of stepped spillways is increasing the performance in energy dissipation. This action will definitely reduce the flow velocity at the spillway toe, which is positively reflected in the choice of the size and type of the stilling basin. This has led to an investigation of the best configurations and features to provide standardized hydraulic design criteria. Recently the features of labyrinth weir have been adopted by Maatooq and Ojaimi (2014) and Maatooq (2016) to modify the step shape in a stepped spillway. The first aim of this modification was to utilize the labyrinth shape to increase the effective width of each step $\left(\mathrm{W}_{\mathrm{L}}\right)$ in comparison with the standard step width (W), where $\mathrm{W}_{\mathrm{L}}=3 \omega(4 \mathrm{a}+2 \mathrm{l} \mathrm{c})$, as evident in Fig. 1(a). The labyrinth shape has the potential to reduce the jet velocities near the flow surface and to reduce the potential of cavitation. At the same time, increasing circulation regions will indeed increase the opportunity of air entrainment, which has the incentive to dissipate more kinetic energy. The second aim was to reduce the volume of construction materials need for each step compared to the traditional step configuration thereby reducing construction cost and time frame.

Accordingly, the aim of this research was to investigate a stepped spillway configuration that can reduce the incoming Froude number by reducing the flow velocity at the spillway toe. The incoming Froude number is an indicator used to classify the type of hydraulic jump often created at the toe of a spillway, and the type of the stilling basin was identified accordingly.

Physical model testing was undertaken of three labyrinths stepped spillways with the labyrinth magnification ratios of $\mathrm{W}_{\mathrm{L}} / \mathrm{W}=1.1,1.2$, and 1.3 as well as testing the conventional stepped spillway $\left(\mathrm{W}_{\mathrm{L}} / \mathrm{W}=1\right)$. This study has focused on investigating the impact of the $\mathrm{W}_{\mathrm{L}} / \mathrm{W}$ ratio on the actual flow velocity at the toe of the spillway.

\section{MODELS AND PROCEDURE}

Physical modelling was undertaken in a flume located at the hydraulic laboratory of the University of Technology-Baghdad. This flume has a working section $0.3 \mathrm{~m}$ wide, $0.45 \mathrm{~m}$ in depth and its length is $12.5 \mathrm{~m}$. Three physical models of the stepped spillway at chute angles, $\theta=35^{\circ}, 45^{\circ}$, and $55^{\circ}$ were adopted with a crest fixed at height $0.32 \mathrm{~m}$ (i.e., the height of dam), these inclination angles gave ratios of step height (h) to step tread length $(\mathrm{s}), \mathrm{h} / \mathrm{s}=0.7,1$, and 1.428, respectively. With each inclination, four-step configurations were tested. The first was a traditional stepped spillway configuration. The other three models were labyrinth step shapes at $n=$ three cycles each of width equal, $\omega$ to give $\mathrm{W}_{\mathrm{L}} / \mathrm{W}=1.1,1.2$, and 1.3 , where the lateral length of labyrinth step $\mathrm{W}_{\mathrm{L}}=\mathrm{n}(4 \mathrm{a}+2 \mathrm{l} \mathrm{c})$, and $\mathrm{W}$ is representing a lateral length of traditional step, see Fig. 1. The twelve models were divided into three groups based on the spillway angle. In all models the step rise, h was kept at $0.04 \mathrm{~m}$, while the tread lengths were, $s=0.057 \mathrm{~m}, 0.04 \mathrm{~m}$, and $0.028 \mathrm{~m}$. The dimensions as illustrated in Fig.1 were selected according to the available hydraulic conditions and flume dimensions.

The flow rate was measured using an electromagnetic flowmeter, which can record flows between 0 to $30 \mathrm{l} / \mathrm{s}$ for accuracy within $\pm 0.01 \mathrm{l} / \mathrm{s}$. Based on the limitation ten different discharges ranged between $2 \mathrm{l} / \mathrm{s}$ and $16 \mathrm{l} / \mathrm{s}$ were selected to achieve flow conditions between nappe and skimming flow regimes. For each run after the stabilizing of the flow, the depths of flow over the crest and at the toe of the spillway were recorded using a digital point gauge with accuracy $\pm 0.1 \mathrm{~mm}$.

The Pitot tube mounted with a water manometer installed on the centre line of the flume was used to measure the velocity at the toe of the spillway for each 
run. This reading is the actual velocity denoted as $V_{a}$. After calibrating the Pitot tube and applying the calibration coefficient, velocity was calculated by;

$$
\mathrm{V}_{\mathrm{a}}=\mathrm{C} \sqrt{2 \mathrm{~g} \Delta \mathrm{h}}
$$

where $\Delta \mathrm{h}$, is the water level difference of the manometer and $\mathrm{C}=0.9$ in this study as determined from calibration.

This actual velocity is compared with the theoretical velocity which calculated from the relationship has been published by Bradley and Paterka (1957), in the form of a chart, its ordinate based on the fall from the reservoir level to the stilling basin floor and its abscissa is the ratio of the actual velocity to the theoretical velocity at the entrance of the stilling basin (toe of spillway). Accordingly, Bradley and Paterka (1957) proposed the following formula for calculating the theoretical velocity;

$$
V_{t}=\sqrt{2 g\left(Z-\frac{H}{2}\right)}
$$

where, $\mathrm{Z}$ is the vertical distance between the elevation of the head, $\mathrm{H}$, over the crest of the spillway and the floor level at the toe of the spillway (see Fig. 2).

The aim of the present study is to assess the functional relationship for the labyrinth coefficient $\left(K_{L}\right)$ which represents the ratio of the actual velocity, $\mathrm{V}_{\mathrm{a}}$ to the theoretical velocity, $\mathrm{V}_{\mathrm{t}}$;

$$
\mathrm{K}_{\mathrm{L}}=\mathrm{V}_{\mathrm{a}} / \mathrm{V}_{\mathrm{t}}
$$

This coefficient depends on the geometrical properties of the spillway surface and the working head over the crest. The lower the value of this coefficient the greater the dissipation of kinetic energy along the surface of the spillway.

\section{RESULTS AND DISCUSSION}

Under conditions of skimming flows down a stepped spillway the flow rotation in the triangular area at a front of the step and on the back of the tread can have a significant impact on energy dissipation. In a conventional stepped spillway, this zone of flow rotation has the same influencing action transversely (i.e., across the width of the spillway). A labyrinth step configuration disrupts this transverse uniformity of flow. The labyrinth step shape can increase the interlocking between a streamwise recirculation as well as a secondary circulation created locally in the labyrinth cycle which definitely increases the ability to dissipate more kinetic energy.

The flow conditions and the hydraulic performance of a stepped spillway are governed by the step height, step length, and discharge (Chanson, 2002; Bose and Hager, 2003; Ohtsu et al., 2004; Khatsuria, 2005). The new concept introduced here is the labyrinth ratio,
$\mathrm{W}_{\mathrm{L}} / \mathrm{W}$. In Fig. 3 the variation of $\mathrm{K}_{\mathrm{L}}$ as the dependent variable under the influence of, $\mathrm{H} / \mathrm{L}$ is illustrated, where $\mathrm{L}$ is the length of the chute (measured along the chute surface) as illustrated in Fig. 1(b). As expected $\mathrm{K}_{\mathrm{L}}$ increases i.e., the velocity at the toe of the spillway becomes closer to the theoretical velocity, as the $\mathrm{H} / \mathrm{L}$ ratio increases, wherewith increasing the head $(\mathrm{H})$ over the crest at the same length of the chute $(\mathrm{L})$ the actual velocity $\left(\mathrm{V}_{\mathrm{a}}\right)$ at the toe definitely increased.

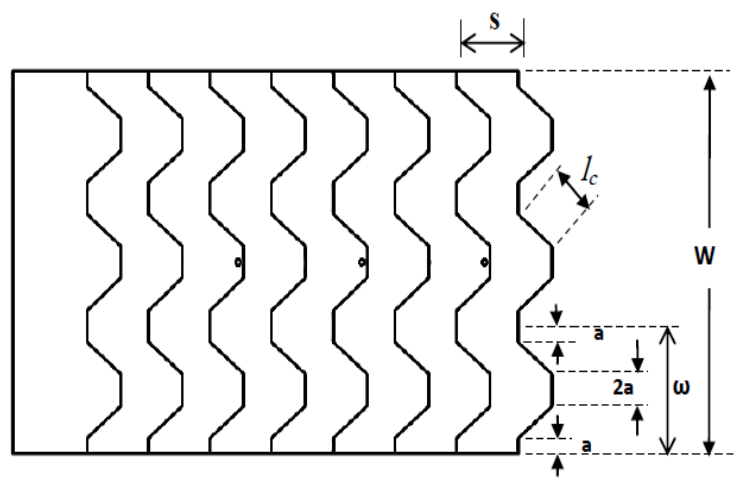

(a)

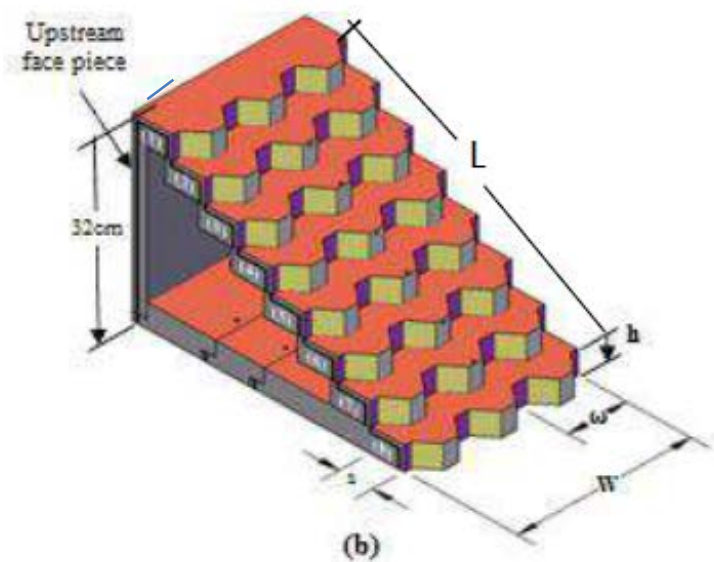

Figure 1. Physical model of labyrinth stepped spillway; (a) Plane view and (b) 3-D view (Maatooq and Ojaimi 2014).

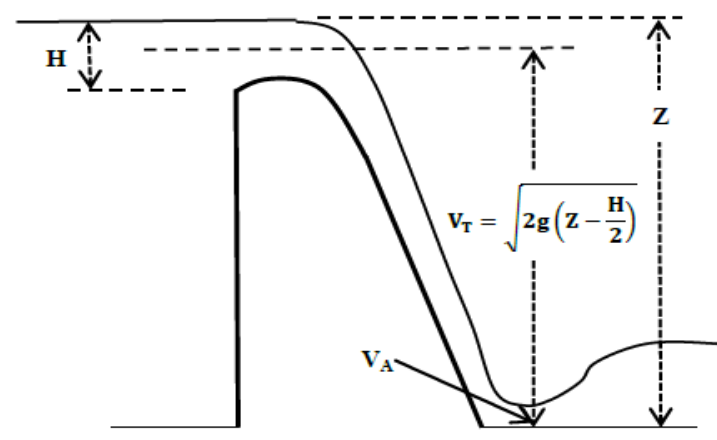

Figure 2. Parameters provided for Eqn. (1) (Bradley and Paterka, 1957). 
This physical point is hydraulically known for such structure through increasing the value of incoming Froude number for the hydraulic jump when it occurs just at the toe of a spillway as evident through a sketch in Fig. 1. Figure 3 illustrates the hydraulic impact of the labyrinth steps where the value of $\mathrm{K}_{\mathrm{L}}$ decreased with increasing the labyrinth ratio $\mathrm{W}_{\mathrm{L}} / \mathrm{W}$ for any given $\mathrm{H} / \mathrm{L}$. This effect seems greater at higher $\mathrm{H} / \mathrm{L}$. This finding is also demonstrated in Fig. 4, where the labyrinth coefficient dramatically decreases as the labyrinth ratio increase for all spillway slope angles. In terms of the effect of inclination or slope angle of the spillway on the labyrinth factor, the $\mathrm{h} / \mathrm{s}=1.428$ $\left(\theta=55^{\circ}\right)$ has a greater influence. The values of $K_{L}$ however, nearly coincide for labyrinth ratio $\mathrm{W}_{\mathrm{L}} / \mathrm{W}=1.3$ when the spillway inclination is between $\theta=35^{\circ}$ and $45^{\circ}$ as shown in Fig. 5. In general, Fig. 5 indicates that for any given value of the labyrinth ratio, $\mathrm{W}_{\mathrm{L}} / \mathrm{W}$ the $\mathrm{h} / \mathrm{s}$ does not have an effective influence on the $K_{\mathrm{L}}$, but at the same time the noticeable influence was inversely proportional instead of the case with the traditional steps.

The statistical software (STATISTICA-10) was used to derive the following functional relationship based on experimental data by multiple nonlinear regression analysis with $\mathrm{R}^{2}=0.921$.

$$
\mathrm{K}_{\mathrm{L}}=1.143\left(\frac{\mathrm{H}}{\mathrm{L}}\right)^{0.329}\left(\frac{\mathrm{W}_{\mathrm{L}}}{\mathrm{W}}\right)^{-0.875}\left(\frac{\mathrm{h}}{\mathrm{s}}\right)^{-0.228}
$$

Equation 4 can be applied with high reliability when the rise of step to the tread $(\mathrm{h} / \mathrm{s})$ is ranged between 0.7 and 1.4, the labyrinth does not exceed 3-cycle, the labyrinth magnification ratio $\left(\mathrm{W}_{\mathrm{L}} / \mathrm{W}\right)$ up to 1.3 , and the lower head over the crest $(\mathrm{H})$ and its maximum value are $5 \%$ to $25 \%$ of the chute length (L) respectively.

Figure (6) demonstrates the relationship between the predicted values of the labyrinth coefficient based on Eqn. (4) and the observed values of this coefficient that resulted through the application of the experimental data at Eqns.1 and 2. It should note here that Eqn. (4) is solely applicable for the labyrinth shape (i.e., $\mathrm{W}_{\mathrm{L}} / \mathrm{W}>1$ ).

For conventional stepped spillway, $\mathrm{W}_{\mathrm{L}}$ is equal to $\mathrm{W}$. Thus the ratio $\mathrm{W}_{\mathrm{L}} / \mathrm{W}$ does not have an effect on $\mathrm{K}_{\mathrm{L}}$. Since the spillway chute here is consisting of traditional steps, the coefficient should take another characterization and denote as Ks. In this situation the effect of two parameters $\mathrm{H} / \mathrm{L}$ and $\mathrm{h} / \mathrm{s}$ has been used in regression analysis to get the following relationship with $\mathrm{R}^{2}=0.938$;

$$
\mathrm{K}_{\mathrm{S}}=1.491\left(\frac{\mathrm{H}}{\mathrm{L}}\right)^{0.449}\left(\frac{\mathrm{h}}{\mathrm{s}}\right)^{-0.174}
$$

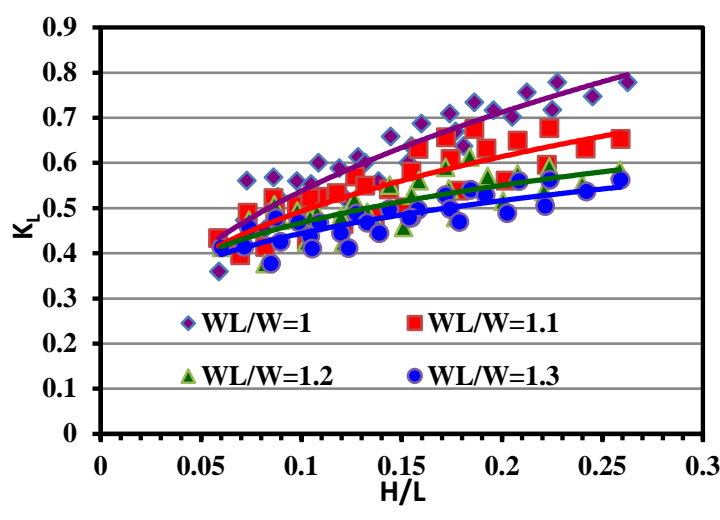

Figure 3. Effect of head over crest related to chute length on labyrinth coefficient $\left(\mathrm{K}_{\mathrm{L}}\right)$.

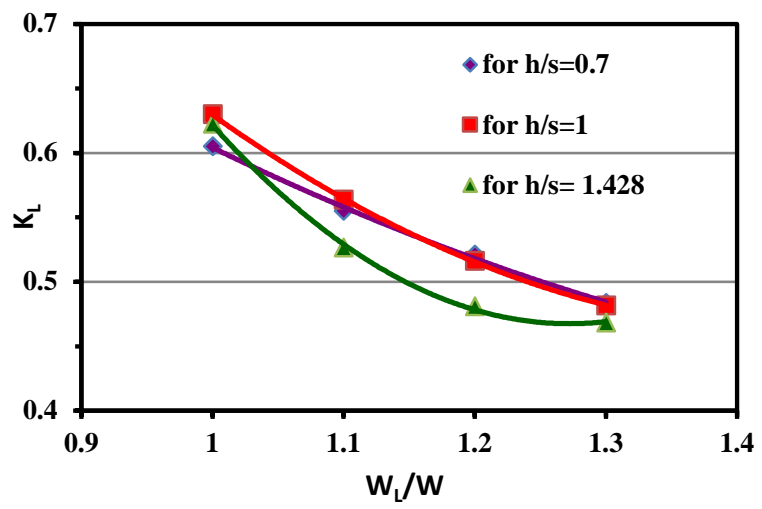

Figure 4. Effect of labyrinth ratio on $\mathrm{K}_{\mathrm{L}}$.

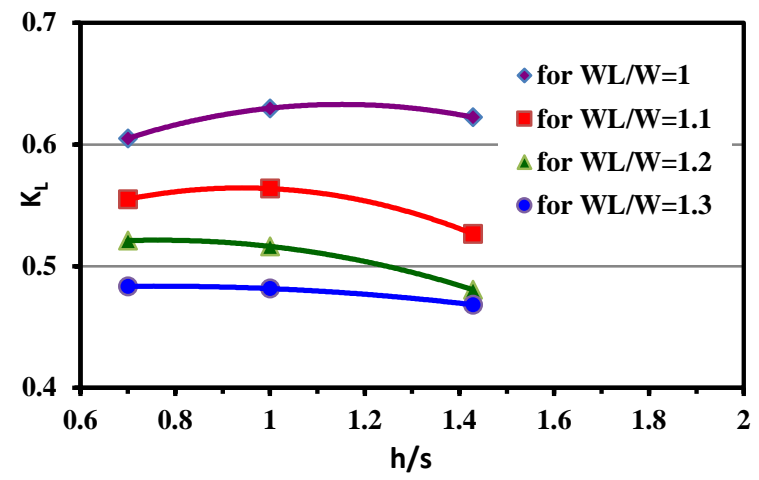

Figure 5. Effect of inclination of the chute on $\mathrm{K}_{\mathrm{L}}$.

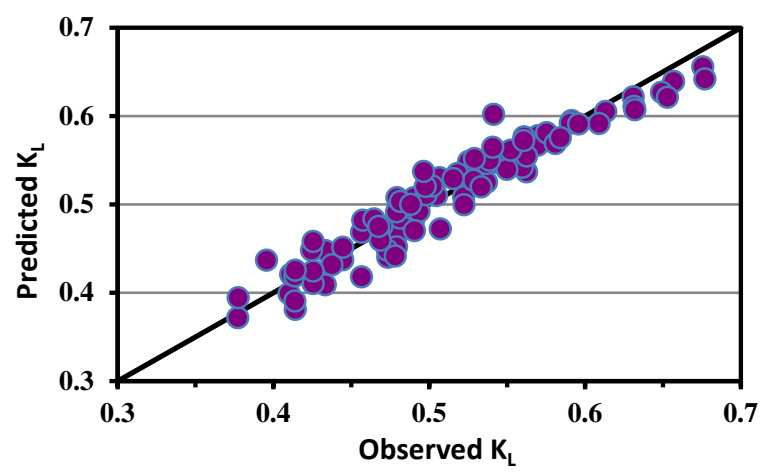

Figure 6. The Predicted versus Observed value of Labyrinth Coefficient. 
Statistical indices including the Root Mean Square Error, RMSE, and the Mean Bias Error, MBE, were also calculated to test the reliability of Eqns.4 and 5. These indicators present error in the units (or square units) of the constituent of interest which aid in the analysis of results. It was first presented by Moriasi, et al. (2007), then cited and adopted by Tariq and Latif (2011), and Maatooq (2016). Zero values of these indicators refer to a perfect fit. Another statistical indicator that determines the relative magnitude of the residual variance compared to the variance of the measured data is the Nash-Sutcliffe Efficiency Coefficient (NSEC) which recommended by the ASCE, 1993. When NSEC has a value between 0 and 1 is viewed as an acceptable performance level, whereas when it being less than zero is an indication of unacceptable performance (less reliability). The statistical measures values of indices for Eqns. 4 and 5 respectively are; $\mathrm{RMSE}=0.0196$ and 0.0252 , MBE $=0.000074$ and 0.000031 . The small values of these indices refer to acceptable correlations. Whereas the NSEC $=0.921$ and 0.938 respectively refer to acceptable reliance. Based on these values of indices it is concluded that Eqns. 4 and 5 could be used as predictive equations to calculate the labyrinth coefficient and stepped spillway chute coefficient (for conventional stepped spillways). Once the value of this coefficient is known the actual flow velocity at the toe of a stepped spillway can easily computing by using Eqn. (2). It should worth noting that the difference between Eqn. (4) and Eqn. (5) is the former used just when $\mathrm{W}_{\mathrm{L}} / \mathrm{W}>1$, i.e. for labyrinth stepped spillway whereas the latter has been derived based on the traditional stepped spillway data.

\section{CONCLUSION}

The velocity at the toe of a spillway is a major variable when designing a stilling basin. Reducing this velocity reduces the required size of a stilling basin with dissipater appurtenances which usually need to dissipate the surplus energy of the flow. If the spillway chute is able to dissipate more kinetic energy then the resulting flow velocity at the toe of the spillway will be reduced. Typically stepped spillway is able to dissipate more kinetic energy than a smooth chute. In the present study, the typical uniform shape of the steps in a spillway has been modified and a labyrinth shape has been adopted. Physical models of three labyrinth stepped spillways with magnification ratios of $\mathrm{W}_{\mathrm{L}} / \mathrm{W}=1.1,1.2$, and 1.3 has been used for experimental work as well as a conventional stepped spillway at which $\mathrm{W}_{\mathrm{L}} / \mathrm{W}=1$.

The experimental results show the significant and direct effect of the labyrinth configuration on decreasing the values of flow velocity at the toe of the spillway. The aim of the experimental work is to establish a simple empirical formula to facilitate the calculation of the flow velocity at the toe of the spillway. Consequently, two empirical forms of the coefficient are proposed, one for labyrinth shape stepped spillway denoted $\mathrm{K}_{\mathrm{L}}$ and another for conventional stepped spillway denoted $\mathrm{K}_{\mathrm{s}}$. Once the value of the coefficient is known the actual flow velocity at the toe of a stepped spillway can easily computing by using Eqn. (2). It should be noted that the labyrinth coefficient calculated by Eqn. (4) has practical limitations such as the labyrinth cycle and the magnification ratio do not exceed 3 and 1.3 respectively along the head over the crest do not exceed the $0.25 \mathrm{~L}$. These boundary conditions are established to further researches to expand the scope of applicability.

\section{CONFLICT OF INTEREST}

The authors declare no conflicts of interest.

\section{ACKNOWLEDGMENT}

The author would like to thank the engineering and technician staff of the Hydraulic Laboratory in the Civil Engineering Dept. at the University of Technology for the help in preparing and installation of physical models. The author acknowledged that some of the readings and recording of the experimental data were conducted by the MSc. student Mr Ojaimi.

\section{REFERENCES}

ASCE (1993), Criteria for evaluation of watershed models. Journal of Irrigation and Drainage Engineering, ASCE 119(3): 429-442.

Abdul-Mehdi TR, Al-Mussawy HA, Al-Madhhachi AST (2016), A laboratory Study Attempt of Flow and Energy Dissipation in Stepped Spillways. Journal of Engineering 22(12):48-64.

Boes RM, Hager WH (2003b), Two-phase Flow Characteristics of Stepped Spillways. Journal of Hydraulic Engineering, ASCE, 129(9):661-670.

Bradley JN, Paterka AJ (1957), The Hydraulic Design of Stilling Basins. Proceeding, ASCE, 83: 29-31.

Chanson H (2002), The Hydraulics of Stepped Chutes and Spillways. Balkema Publishers, Steenwijk, The Netherlands.

El-Jumaily KK, Al-Lami MK (2009), Study of Conveniency of Using Stepped Spillway in Roller Compacted Concrete Dams (RCCD). Engineering and Technology Journal 27(16), http://www.uotechnology.edu.iq/tec_magaz/issues 2009.htm.

Khatsuria RM (2005), Hydraulic of Spillway and Energy Dissipators. Marcel Dekker, New York, USA, ISBN: 0-8247-5789-0.

Maatooq JS, Ojaimi TJ (2014), Evaluation the Hydraulic Aspects of Stepped Labyrinth Spillway. Engineering and Technology Journal 32(9)(Ppart-A): 2174-2185.

Maatooq JS (2016), Kinetic Energy Dissipation on Labyrinth Configuration Stepped Spillway. Tikrit 
Journal of Engineering Sciences 23(3): 12-24.

Manso PA, Schleiss AJ (2002), Stability of Concrete Macro-Roughness Linings for Overflow Protection of Earth Embankment Dams. Canadian Journal of Civil Enggineers 29(5): 762-776.

Moghddam AK, Ketabdar M, Ahmadian SA, Hoseini P, Pishdadakhgari M (2017), Experimental Survey of Energy Dissipation in Nappe flow Regime in Stepped Spillway Equipped with Inclined Steps and Sill. International Journal of Research and Engineering 4(5): 161-165.

Moriasi DN, Arnold JG, Van Liew MW, Bingner RL, Harmel RD, Veith TL (2007), Model evaluation guidelines for systematic quantification of accuracy in watershed simulations. Transaction of
ASABE 50(3): 885-900.

Ohtsu I, Yasuda Y, Takahashi M (2004), Flow Characteristics of Skimming Flows in Stepped Channels. Journal of Hydraulic Engineering, ASCE, 130(9): 860-869.

Tariq JA, Latif M (2011), Flexibility Analysis of Irrigation Outlet Structures using Simulation of Irrigation Canal Hydrodynamic Model. Irrigation Science 29: 127-134, DOI 10.1007/s00271-010-0222-8.

Zahra A, Afzalimehr H, Singh VP, Fattahi R (2015), Prediction of flow velocity near inclined surfaces with varying roughness. International Journal of Hydraulic Engineering 4(1): 1-9. 